Research article

Open Access

\title{
Diurnal secretion of growth hormone, cortisol, and dehydroepiandrosterone in pre- and perimenopausal women with active rheumatoid arthritis: a pilot case-control study
}

\author{
Marc R Blackman1, Ranganath Muniyappa1, Mildred Wilson², Barbara E Moquin1, \\ Howard L Baldwin1, Kelli A Wong1, Christopher Snyder², Michael Magalnick², Shaan Alli2, \\ James Reynolds ${ }^{3}$, Seth M Steinberg ${ }^{4}$ and Raphaela Goldbach-Mansky²
}

\begin{abstract}
${ }^{1}$ Endocrine Section, Laboratory of Clinical Investigation, National Center for Complementary and Alternative Medicine, National Institutes of Health, 9000 Rockville Pike, Bethesda, MD 20892, USA

${ }^{2}$ Office of the Clinical Director, National Institute of Arthritis and Musculoskeletal and Skin Diseases, National Institutes of Health, 9000 Rockville Pike, Bethesda, MD 20892, USA

3Department of Radiology, Warren Magnuson Clinical Center, National Institutes of Health, 9000 Rockville Pike, Bethesda, MD 20892, USA

4Biostatistics and Data Management Section, Center for Cancer Research, National Cancer Institute, National Institutes of Health, 9000 Rockville

Pike, Bethesda, MD 20892, USA
\end{abstract}

Corresponding author: Marc R Blackman, Marc.Blackman@va.gov

Received: 12 Mar 2007 Revisions requested: 17 Apr 2007 Revisions received: 28 Jun 2007 Accepted: 28 Jul 2007 Published: 28 Jul 2007

Arthritis Research \& Therapy 2007, 9:R73 (doi:10.1186/ar2271)

This article is online at: http://arthritis-research.com/content/9/4/R73

(c) 2007 Blackman et al.; licensee BioMed Central Ltd.

This is an open access article distributed under the terms of the Creative Commons Attribution License (http://creativecommons.org/licenses/by/2.0), which permits unrestricted use, distribution, and reproduction in any medium, provided the original work is properly cited.

\begin{abstract}
Rheumatoid arthritis (RA) is associated with neuroendocrine and immunologic dysfunction leading to rheumatoid cachexia. Although excess proinflammatory cytokines can decrease somatotropic axis activity, little is known about the effects of RA on growth hormone/insulin-like growth factor-1 (GH/IGF-I) axis function. We tested the hypothesis that patients with active RA exhibit decreased GH/IGF-I axis activity. To do so, we conducted a pilot case-control study at a clinical research center in 7 pre- and perimenopausal women with active RA and 10 age- and body mass index-matched healthy women. Participants underwent blood sampling every 20 minutes for 24 hours ( 8 a.m. to 8 a.m.), and sera were assayed for $\mathrm{GH}$, cortisol, and dehydroepiandrosterone (DHEA). Sera obtained after overnight fasting were assayed for IGF-I, IGF-binding protein (IGFBP)-1, IGFBP-3, C-reactive protein (CRP), interleukin-6 (IL-

absorptiometry) scans. In patients with RA, mean disease duration was $7.6 \pm 6.8$ years, and erythrocyte sedimentation rate, CRP, and IL- 6 were elevated. GH half-life was shorter than in control subjects $(p=0.0037)$, with no other significant group differences in $\mathrm{GH}$ deconvolution parameters or approximate entropy scores. IGF-I $(p=0.05)$ and IGFBP-3 $(p=0.058)$ were lower, whereas IGFBP-1 tended to be higher $(p=0.066)$, in patients with RA, with nonsignificantly increased 24-hour total $\mathrm{GH}$ production rates. There were no significant group differences in cortisol or DHEA secretion. Lean body mass was lower in patients with RA $(p=0.019)$, particularly in the legs ( $p$ $=0.01$ ). Women with active RA exhibit a trend toward GH insensitivity and relatively diminished diurnal cortisol and DHEA secretion for their state of inflammation. Whether these changes contribute to rheumatoid cachexia remains to be determined.
\end{abstract} 6), glucose, insulin, and lipids. Body composition and bone mineral density were evaluated by DEXA (dual emission $x$-ray
Trial registration number NCT00034060.

\section{Introduction}

Rheumatoid arthritis (RA) is a chronic, autoimmune-mediated, inflammatory arthritis that occurs in approximately $0.5 \%$ to $1 \%$ of the general population and affects women 2.5 times more often than it does men. Chronic imbalance among neuroendocrine, immunologic, and microvascular systems leads to 'rheu-

$\overline{\mathrm{ACTH}}=$ adrenocorticotropic hormone; $\mathrm{ApEn}=$ approximate entropy; BMD = bone mineral density; BMI = body mass index; $\mathrm{CRH}=$ corticotropinreleasing hormone; $\mathrm{CRP}=\mathrm{C}$-reactive protein; $\mathrm{CV}=$ coefficient of variation; $\mathrm{DEXA}=$ dual energy $\mathrm{x}$-ray absorptiometry; $\mathrm{DHEA}=$ dehydroepiandrosterone; $\mathrm{ESR}=$ erythrocyte sedimentation rate; $\mathrm{FSH}=$ follicle-stimulating hormone; GFR = glomerular filtration rate; $\mathrm{GH}=$ growth hormone; $\mathrm{HDL}=$ high-density lipoprotein; HPA = hypothalamic-pituitary-adrenal; IGF-I= insulin-like growth factor-1; IGFBP = insulin-like growth factor-binding protein; IL-6 = interleukin-6; IV = intravenous; LBM = lean body mass; MDRD = Modification of Diet in Renal Disease; NIH = National Institutes of Health; RA $=$ rheumatoid arthritis; $\mathrm{RIA}=$ radioimmunoassay; TNF = tumor necrosis factor. 
matoid cachexia,' accelerated cardiovascular disease, and enhanced mortality in patients with RA [1-3]. RA cachexia is manifested by losses of muscle and bone mass, resulting in part from augmented cytokine activity [4].

Progressive decline in the secretion of growth hormone (GH) and its principal circulating and tissue mediator, insulin-like growth factor-1 (IGF-I), is one of the key pathophysiological mechanisms contributing to the cachexia of normal aging [5]. In a mouse model, overexpression of the inflammatory cytokine, interleukin-6 (IL-6), has been associated with suppression of the GH/IGF-I axis [6]. However, few studies have investigated the GH/IGF-I axis in patients with active RA [7]. The hypothalamic-pituitary-adrenal (HPA) axis is also affected to varying degrees in patients with $R A$, independent of the use of exogenous glucocorticoids. Most reports indicate that circulating levels of cortisol and dehydroepiandrosterone (DHEA) are normal, and not elevated, in the setting of increased proinflammatory activity, suggesting a relative hypoadrenalism in patients with RA, possibly due to reduced corticotropin-releasing hormone $(\mathrm{CRH})$ activity $[8,9]$.

We hypothesized that the excess of systemically released inflammatory cytokines characteristic of patients with active RA suppresses GH/IGF-I axis activity and that the combined effects of disordered endocrine (anabolic balance) and immune function contribute to changes in body composition predisposing patients with RA to sarcopenia, increased body fat, and osteopenia. The primary goal of this study was to determine whether spontaneous, diurnal $\mathrm{GH}$ secretion and a.m serum IGF-I concentrations are decreased in pre- and perimenopausal women with active RA. In addition, we evaluated ultradian and pulsatile cortisol and DHEA secretory dynamics, body composition, and metabolic outcomes in these same patients and compared them with values in healthy control subjects.

\section{Materials and methods Study subjects}

We recruited seven premenopausal and perimenopausal women who fulfilled the American College of Rheumatology criteria for active RA as defined by at least nine tender and six swollen joints, erythrocyte sedimentation rate (ESR) of greater than $28 \mathrm{~mm} /$ hour or C-reactive protein (CRP) of greater than $2.0 \mathrm{mg} / \mathrm{dl}$, and morning stiffness of greater than 45 minutes. Use of nonsteroidal anti-inflammatory drugs and/or hydroxychloroquine was permitted. However, drug doses had to have been stable for at least 1 month prior to enrollment and they were held constant during the study unless toxicity required dose reduction. Patients were allowed to be on stable doses of methotrexate, but past use of all other disease-modifying agents (for example, sulfasalazine or cyclosporin) or anti-tumor necrosis factor (TNF) agents (for example, etanercept or infliximab) or glucocorticoid was allowed only if (a) the total exposure had not been more than 3 months and (b) there had been no exposure in the 3 months prior to enrollment. No patients were using alternative treatments such as nutritional supplements, acupuncture, or chiropractic therapy, and all were physically active. At the time of study screening, all patients with RA were either premenopausal, as defined by a history of normal menses and normal estradiol (>30 pg/ml) plus folliclestimulating hormone (FSH) levels, or perimenopausal, with a history of irregular menses during the 12 months prior to study and normal estradiol (>30 pg/ml) plus elevated $\mathrm{FSH}$ (>30 IU/ $\mathrm{ml}$ ) levels. Ten healthy women matched for age ( \pm 3 years), body mass index (BMI) $( \pm 1.0)$, and menstrual and reproductive hormone status were also included. Research subjects were excluded if they were obese $(\mathrm{BMI}>30)$, had used prescription or over-the-counter estrogen/progesterone preparations during the 2 weeks prior to screening, were pregnant, or had a history of cancer, renal disease, liver disease, anemia, endocrine or metabolic disorders, active infections or live vaccinations (in the 3 months prior to enrollment), depression, or any other comorbid medical or psychiatric condition known to influence the GH-IGF-I or HPA axis. The study was approved by the Institutional Review Board of the National Institute of Diabetes and Digestive and Kidney Diseases and the National Institute of Arthritis and Musculoskeletal and Skin Diseases, National Institutes of Health (NIH), and all participants provided written informed consent.

\section{Study design}

Study participants were admitted to the Clinical Research Center on the evening of day 1 to allow overnight adaptation and provision of their usual ad libitum diet in the form of a light dinner. Participants then remained fasting overnight. At 7 a.m. on day 2, an intravenous (IV) catheter was inserted into a forearm vein and was kept open with $0.9 \%$ sodium chloride. At 8 a.m., after the overnight fast, $30 \mathrm{ml}$ of blood was collected for measurements of serum IGF-I, IGF-binding protein (IGFBP)-1 and IGFBP-3, glucose, insulin, lipid profile, CRP, and IL-6. From 8 a.m. on day 2 to 8 a.m. on day 3 , blood samples ( 2.5 $\mathrm{ml}$ ) were collected at 20-minute intervals, and sera were stored at $-80^{\circ} \mathrm{C}$ for subsequent measurements of $\mathrm{GH}$, cortisol, and DHEA. On the morning of day 3 , at the completion of the 24-hour frequent blood sampling, the IV catheter was removed, and study participants were asked to complete a visual analog scale for pain and global health. Anthropometric measurements, including body weight, height, and BMI, were obtained, and a dual energy $x$-ray absorptiometry (DEXA) scan (Hologic QDR 4500; Hologic Inc., Bedford, MA, USA) was performed to assess total and regional lean body mass (LBM), total fat mass, and bone mineral density (BMD) at six sites (postero-anterior spine, total femur, femoral neck, trochanter, Ward's area, and distal radius). Participants were discharged early in the afternoon of day 3.

\section{Biochemical assays}

Serum obtained at 8 a.m. after an overnight fast was used for measurements of IGF-I, IGFBP-1 and IGFBP-3, CRP, and IL- 
6. $\mathrm{GH}$ and cortisol concentrations were measured in sera obtained from the 24-hour (every 20 minutes) sampling technique by means of a chemiluminescence assay (Nichols Institute Diagnostics Inc., San Clemente, CA, USA). Sensitivity and intra- and interassay coefficients of variation (CVs) of the GH assay were $0.1 \mathrm{ng} / \mathrm{ml}$ and $2.8 \%$ and $7.5 \%$, respectively. Corresponding values for the cortisol assay were $0.9 \mu \mathrm{g} / \mathrm{dl}$ and $4.4 \%$ and $11 \%$, respectively. IGF-I, IGFBP-1, and IGFBP3 were measured at Endocrine Sciences (Tarzana, CA, USA). IGF-I was measured by a blocking radioimmunoassay (RIA) after acid alcohol extraction. IGFBP-1 and IGFBP-3 were measured by RIA in dilute serum. The sensitivity of the IGF-I assay was $63.4 \mathrm{ng} / \mathrm{ml}$, and intra- and inter-assay CVs were $6.5 \%$ and $9.4 \%$, respectively. Corresponding values for the IGFBP-1 assay were $5 \mathrm{ng} / \mathrm{ml}$, with intra- and inter-assay CVs of $6 \%$ and $12 \%$, and those for the IGFBP-3 assay were 0.8 $\mathrm{mg} / \mathrm{l}$, with intra- and inter-assay CVs of $13 \%$ and $17 \%$, respectively. Serum levels of DHEA were measured in the every-20minute sampling specimens by enzyme-linked immunosorbent assay at Diagnostic Systems Laboratories (Webster, TX, USA). The sensitivity of the assay was $0.1 \mathrm{ng} / \mathrm{ml}$, with intraand interassay CVs of $10.7 \%$ and $17.0 \%$, respectively. DHEA measurements correlated strongly $\left(r^{2}=0.87\right)$ with values quantified by tandem gas chromatography-mass spectrometry. IL-6 was measured using commercially available kits (Quantikine HS Human IL-6 Immunoassay; R\&D Systems, Inc., Minneapolis, MN, USA). The sensitivity of the IL- 6 assay was $0.039 \mathrm{pg} / \mathrm{ml}$ with intra- and inter-assay CVs of $7.8 \%$ and $7.2 \%$, respectively. Serum concentrations of CRP were measured in the NIH Clinical Center's Department of Laboratory Medicine by high-sensitivity nephelometric assay on an IMMAGE Immunochemistry System (Beckman Coulter, Fullerton, CA, USA). The sensitivity was $0.1 \mathrm{mg} / \mathrm{dl}$ and the intra- and interassay CVs were $2.6 \%$ and $3.0 \%$, respectively. Serum concentrations of glucose, insulin, total and high-density lipoprotein (HDL) cholesterol, and triglycerides were measured by routine chemical techniques in the NIH Clinical Center's Department of Laboratory Medicine.

\section{Analysis of hormone secretion}

Multi-parameter deconvolution analysis (Deconv) was applied to determine quantitative properties of underlying secretory bursts and endogenous hormone half-life of $\mathrm{GH}$, cortisol, and DHEA [10]. Regularity in GH, cortisol, or DHEA concentration-time series was quantified using approximate entropy (ApEn) as previously described [11].

Twenty-four-hour rhythmicity of serum GH, cortisol, or DHEA concentrations was quantified by cosinor analysis [12]. This procedure entails unweighted regression of a cosine function of 1,440-minute periodicity on the observed hormone concentration-time series. Ninety-five percent statistical confidence intervals are determined for the fitted amplitude $(50 \%$ of the nadir-zenith difference), mesor (cosine mean), and acrophase (clock time of calculated maximum value).

\section{Statistical analysis}

After verification of lack of difference between women with RA and their healthy controls with respect to age and $\mathrm{BMI}$, an exact Wilcoxon rank sum test was used to compare results between groups. $P$ values for the primary outcome measures (total GH level and IGF-I) were adjusted for multiple comparisons by the Hochberg method and considered significant if the $p$ value was less than 0.05 [13]. Planned secondary parameters (IGFBPs, IL-6, DHEA, cortisol, and metabolic and lipid parameters) were considered significant if the $p$ value was less than 0.01 . When unplanned exploratory parameters (DEXA measurements of body fat and BMD) were compared between groups, a $p$ value of less than 0.005 was considered significant.

\section{Results \\ Patient characteristics}

There were no significant differences in age or BMl between patients with RA and control subjects. Patients with RA were predominantly Hispanic-American and African-American, whereas control subjects were primarily Caucasian and African-American. Patients with RA had experienced their disease for a mean \pm standard error of the mean of $7.6 \pm 2.6$ years, had $23.2 \pm 3.7$ swollen joints and $23.3 \pm 2.8$ tender joints, had increased pain and physical component summary scores, and exhibited elevated values for ESR, CRP, and IL-6 (Table 1).

\section{Hormone measures}

Except for a shorter GH half-life in patients with RA, there were no significant differences in circadian $\mathrm{GH}$ deconvolution parameters or ApEn scores in patients with RA versus control subjects (Table 2). However, in RA patients as compared with their healthy counterparts, the mean serum concentration of IGF-I in the morning was lower ( $p=0.05)$, IGFBP-3 exhibited a trend toward being lower, and IGFBP-1 concentrations tended to be higher. The changes in IGF-I and IGFBPs in patients with RA were associated with nonsignificantly higher 24-hour total $\mathrm{GH}$ production rates.

We also examined the circadian characteristics of cortisol and DHEA secretion. There were no significant differences in the total production rate, mean or integrated concentrations, or regularity (ApEn) of circadian cortisol or DHEA secretion in RA patients compared with healthy control subjects (Table 3 ). The amplitudes and acrophases of 24-hour cortisol or DHEA rhythms were also similar in the two groups (data not shown).

\section{Body composition and metabolic profile}

Total LBM, determined by DEXA, was lower in patients with RA versus control subjects, with disproportionately greater reductions in the legs versus the arms (Table 4). In contrast, there were no significant group differences in absolute or percentage total fat mass or in BMD values of the spine, hip, or radius (Table 4). After an overnight fast, serum creatinine and (to a lesser extent) total cholesterol concentrations were 
Table 1

Characteristics of patients with rheumatoid arthritis

\begin{tabular}{|c|c|c|}
\hline Variables & Rheumatoid arthritis $(n=7)$ & Controls $(n=10)$ \\
\hline Age (years) & $36.3 \pm 3.7$ & $41.8 \pm 2.1$ \\
\hline \multicolumn{3}{|l|}{ Race $(n)$} \\
\hline Caucasian & 0 & 6 \\
\hline Hispanic & 5 & 0 \\
\hline African-American & 2 & 4 \\
\hline Duration of rheumatoid arthritis (years) & $7.6 \pm 2.6$ & NA \\
\hline Swollen joint count ${ }^{a}$ & $23.2 \pm 3.7$ & NA \\
\hline Tender joint count ${ }^{\mathrm{a}}$ & $23.3 \pm 2.8$ & NA \\
\hline Swollen joint score ${ }^{a}$ & $31.7 \pm 6.1$ & NA \\
\hline Tender joint score ${ }^{a}$ & $34.0 \pm 5.5$ & NA \\
\hline Pain (visual analog) scores ${ }^{b}$ & $7.1 \pm 0.6$ & NA \\
\hline Physical component summary score ${ }^{c}$ & $28.0 \pm 2.1$ & $55.3 \pm 1.3$ \\
\hline Erythrocyte sedimentation rate ( $\mathrm{mm} /$ hour) & $69.1 \pm 11.3$ & $15.9 \pm 1.6$ \\
\hline C-reactive protein $(\mathrm{mg} / \mathrm{dl})$ & $3.7 \pm 1.3$ & $0.4 \pm 0.02$ \\
\hline Interleukin-6 (pg/ml) & $25.6 \pm 9.8$ & $5.3 \pm 2.4$ \\
\hline
\end{tabular}

Values are presented as mean \pm standard error of the mean. NA, not applicable. aSixty-eight joints were examined for tenderness, and 66 joints

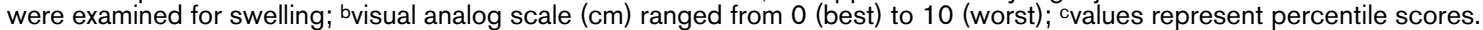

Table 2

GH secretory parameters and morning serum concentrations of IGF-I and IGFBPs in rheumatoid arthritis patients and control subjects

\begin{tabular}{|c|c|c|c|}
\hline Variables & Rheumatoid arthritis $(n=7)$ & Controls $(n=10)$ & $P$ value \\
\hline $\mathrm{GH}$ basal secretion ( $\mu \mathrm{g} /$ liter per minute) & $0.02 \pm 0.00$ & $0.01 \pm 0.00$ & NS \\
\hline GH mass/burst ( $\mu \mathrm{g} /$ liter $)$ & $6.12 \pm 1.03$ & $6.71 \pm 1.20$ & NS \\
\hline GH burst frequency (number/24 hours) & $13.7 \pm 1.9$ & $9.8 \pm 1.2$ & NS \\
\hline $\mathrm{GH}$ amplitude ( $\mu \mathrm{g} /$ liter per minute) & $0.430 \pm 0.10$ & $0.29 \pm 0.06$ & NS \\
\hline $\mathrm{GH}$ total production rate ( $\mu \mathrm{g} /$ liter per 24 hours) & $114 \pm 26$ & $73 \pm 74$ & 0.28 \\
\hline Mean GH ( $\mu \mathrm{g} /$ liter) & $0.91 \pm 0.14$ & $1.20 \pm 0.17$ & NS \\
\hline Integrated GH ( $\mu \mathrm{g} /$ liter per minute) & $1,316 \pm 201$ & $1,717 \pm 245$ & NS \\
\hline GH half-life (minutes) & $9.2 \pm 1.2$ & $14.6 \pm 0.9$ & 0.0037 \\
\hline GH approximate entropy & $0.75 \pm 0.07$ & $0.70 \pm 0.09$ & NS \\
\hline IGF-I (ng/ml) & $129 \pm 27$ & $205 \pm 25$ & 0.05 \\
\hline IGFBP-1 (ng/ml) & $42.1 \pm 16$ & $8.3 \pm 2$ & 0.066 \\
\hline IGFBP-3 (ng/ml) & $2.2 \pm 0.2$ & $2.6 \pm 0.1$ & 0.058 \\
\hline
\end{tabular}

Values are presented as mean \pm standard error. $P$ value indicates the significance of the difference in each parameter value between patients and control subjects. See 'Statistical analysis' section for details. GH, growth hormone; IGF-I, insulin-like growth factor-1; IGFBP, insulin-like growth factor-binding protein; NS, not significant ( $p>0.10$ when not explicitly reported). 
Table 3

Diurnal cortisol and dehydroepiandrosterone secretory parameters in rheumatoid arthritis patients and control subjects

\begin{tabular}{|c|c|c|c|c|}
\hline \multirow[b]{2}{*}{ Variables } & \multicolumn{2}{|c|}{ Cortisol ( $\mu \mathrm{g} / \mathrm{dl})$} & \multicolumn{2}{|c|}{ Dehydroepiandrosterone (ng/ml) } \\
\hline & $\begin{array}{l}\text { Rheumatoid arthritis } \\
\qquad(n=7)\end{array}$ & $\begin{array}{l}\text { Controls } \\
(n=10)\end{array}$ & $\begin{array}{l}\text { Rheumatoid arthritis } \\
\qquad(n=7)\end{array}$ & $\begin{array}{l}\text { Controls } \\
n=10)\end{array}$ \\
\hline Total production rate (per 24 hours) & $71 \pm 8$ & $75 \pm 7$ & $280 \pm 108$ & $203 \pm 50$ \\
\hline Mean concentration & $7.12 \pm 0.62$ & $6.48 \pm 0.33$ & $7.02 \pm 2.28$ & $6.76 \pm 0.89$ \\
\hline Integrated concentration (per minute) & $10,094 \pm 841$ & $9,218 \pm 598$ & $9,950 \pm 3,252$ & $9,401 \pm 1,275$ \\
\hline Approximate entropy & $0.93 \pm 0.08$ & $0.91 \pm 0.08$ & $1.22 \pm 0.08$ & $1.18 \pm 0.06$ \\
\hline
\end{tabular}

Values are presented as mean \pm standard error. All of the differences had $p$ values greater than 0.10 .

Table 4

Body composition and metabolic outcomes in rheumatoid arthritis patients and control subjects

\begin{tabular}{|c|c|c|c|}
\hline Variables & Rheumatoid arthritis $(n=7)$ & Controls $(n=10)$ & $P$ value \\
\hline Body mass index $\left(\mathrm{kg} / \mathrm{m}^{2}\right)$ & $26.9 \pm 0.9$ & $27.8 \pm 0.9$ & NS \\
\hline Total lean body mass $(\mathrm{kg})$ & $40.3 \pm 1.1$ & $46.1 \pm 1.6$ & 0.019 \\
\hline Lean body mass, both arms (kg) & $3.9 \pm 0.3$ & $4.6 \pm 0.2$ & 0.03 \\
\hline Lean body mass, both legs (kg) & $12.5 \pm 0.4$ & $15.4 \pm 0.7$ & 0.01 \\
\hline Total body fat mass $(\mathrm{kg})$ & $23.7 \pm 0.8$ & $25.8 \pm 1.5$ & NS \\
\hline Body fat (percentage) & $35.9 \pm 1.1$ & $34.6 \pm 1.0$ & NS \\
\hline \multicolumn{4}{|l|}{ Bone mineral density $\left(\mathrm{g} / \mathrm{cm}^{2}\right)^{a}$} \\
\hline Femoral neck & $0.85 \pm 0.03$ & $0.82 \pm 0.05$ & NS \\
\hline Trochanter & $0.69 \pm 0.03$ & $0.75 \pm 0.05$ & NS \\
\hline Ward's area & $0.74 \pm 0.03$ & $0.74 \pm 0.06$ & NS \\
\hline Lumbar spine (L2-L4) & $0.790 \pm 0.03$ & $0.81 \pm 0.04$ & NS \\
\hline Distal radius & $0.68 \pm 0.01$ & $0.72 \pm 0.02$ & NS \\
\hline Serum creatinine (mg/dl) & $0.57 \pm 0.05$ & $0.79 \pm 0.02$ & $<0.001$ \\
\hline Fasting blood glucose (mg/dl) & $90.6 \pm 1.9$ & $91.7 \pm 2.2$ & NS \\
\hline Fasting insulin ( $\mu \mathrm{U} /$ liter $)$ & $11.20 \pm 3.60$ & $7.40 \pm 0.70$ & NS \\
\hline $\begin{array}{l}\text { Quantitative Insulin Sensitivity } \\
\text { Check Index }\end{array}$ & $0.35 \pm 0.01$ & $0.36 \pm 0.01$ & NS \\
\hline Total cholesterol (mg/dl) & $156 \pm 13$ & $198 \pm 13$ & 0.046 \\
\hline $\begin{array}{l}\text { Low-density lipoprotein } \\
\text { cholesterol (mg/dl) }\end{array}$ & $96.6 \pm 11.2$ & $124.4 \pm 13.3$ & NS \\
\hline $\begin{array}{l}\text { High-density lipoprotein } \\
\text { cholesterol (mg/dl) }\end{array}$ & $47.90 \pm 5.30$ & $57.7 \pm 4.2$ & NS \\
\hline Triglycerides (mg/dl) & $97.6 \pm 9.2$ & $109.3 \pm 11.5$ & NS \\
\hline
\end{tabular}

Values are presented as mean \pm standard error. $P$ value indicates the significance of the difference in each parameter value between patients and control subjects. aOne patient with rheumatoid arthritis was removed from the bone mineral density analysis because of her diagnosis of osteosclerosis. NS, not significant $(p>0.10)$. 
lower, whereas serum insulin concentrations were slightly but nonsignificantly higher in patients with RA; there were no group differences in glucose, QUICKI (Quantitative Insulin Sensitivity Check Index), low-density lipoprotein or HDL cholesterol, or triglyceride values.

\section{Discussion}

In this study, a well-characterized group of pre- and perimenopausal women with clinically and biochemically active RA, compared with age- and BMl-matched healthy women, exhibited reduced morning serum concentrations of IGF-I, a trend toward lower IGFBP-3, accelerated GH circulatory half-life, trends toward increases in IGFBP-1 and IL- 6 levels (and total $\mathrm{GH}$ production), unaltered pulsatile, nycthemeral, or feedbacksensitive (entropic) features of cortisol or DHEA secretion, and substantially decreased LBM, especially in the legs.

Studies evaluating the GH-IGF-I-IGFBP-3 system in patients with RA have yielded contradictory and inconsistent results [7,9,13-18], in part because of differences in the ages, genders, and numbers of patients studied, disease activity, and use of glucocorticoids and other disease-modifying agents. In the current investigation, the mean serum concentration of IGF-I in the morning was lower in patients with RA versus control subjects and IGFBP-3 also exhibited a similar trend, findings consistent with some studies $[15,16]$ but not with others $[18,19]$. In the latter four studies, there were no apparent relationships between disease activity and IGF-I and IGFBP-3 levels. Most circulating IGF-I is produced by the liver in response to $\mathrm{GH}$ and mediates many of the anabolic actions of $\mathrm{GH}$. In comparison, local IGF-I production within target tissues is regulated by both $\mathrm{GH}$-dependent and -independent mechanisms. IGF-I circulates as a ternary complex with IGFBP-3 and the acid-labile subunit, and both liver-derived proteins are under the control of $\mathrm{GH}$ [20]. Reduced serum concentrations of IGFBP-3 can result from a primary decrease in IGFBP-3 production, or secondarily, due to a reduction in IGF-I. IGFBP-3 stabilizes circulating IGF-I, and reductions in IGFBP-3 can contribute to a decrease in IGF-I levels (due to decreased stability of the complex). IGFBP-1, which is also derived from the liver, binds to free IGF-I and is negatively regulated by nutrition and insulin [20]. Elevated IGFBP-1 levels as observed in patients with RA could further reduce free IGF-I availability and action [21].

In this study, mean $\mathrm{GH}$ concentrations in patients with RA were not significantly different from those in age- and BMImatched healthy volunteers. However, the nonsignificant increase in $\mathrm{GH}$ total production rate which we observed was accompanied by a significant reduction in the calculated $\mathrm{GH}$ half-life in patients with RA, and that may explain the unchanged mean and integrated circulating $\mathrm{GH}$ concentrations. Circulating $\mathrm{GH}$ is cleared primarily by the liver and kidney. The rate of $\mathrm{GH}$ elimination is directly related to the plasma total free $\mathrm{GH}$ concentration, relative obesity, and renal function
[22]. The exact mechanism (or mechanisms) of the reduced $\mathrm{GH}$ half-life in our patients with RA is unclear, and the apparent change in calculated $\mathrm{GH}$ elimination kinetics in patients with $\mathrm{RA}$ requires further confirmation by more robust, isotopic infusion techniques. However, some potential factors may explain the reduced $\mathrm{GH}$ half-life in our patients with RA. GH is catabolised in the kidney after filtration and absorption by the proximal tubules. Consequently, $\mathrm{GH}$ clearance rate is determined by the glomerular filtration rate (GFR). In this study, estimated GFR (using the LBM-adjusted Cockcroft and Gault formula or the formula derived from the Modification of Diet in Renal Disease [MDRD] study [23,24]) was higher in RA patients as compared with healthy volunteers (MDRD-derived GFR: $123.9 \pm 14.2$ versus $77.2 \pm 8.1 \mathrm{ml} /$ minute per $1.73 \mathrm{~m}^{2}$; $p=0.0015)$. This may have contributed to the shortened $\mathrm{GH}$ half-life. In addition, GH half-life is determined by the volume of distribution. In this study, LBM is significantly reduced in RA patients as compared with healthy controls. Consequently, it is possible that the volume of distribution for $\mathrm{GH}$ is also reduced. Thus, increased renal clearance and reduced volume of distribution may enhance $\mathrm{GH}$ elimination. Of note, renal impairment in RA occurs late in the course of disease and is increased in patients who develop vasculitis or amyloidosis or as a complication from drug therapy. The most potentially nephrotoxic agents - gold salts, penicillamine, and cyclosporine - are no longer commonly used. Thus, the finding of reduced $\mathrm{GH}$ half-life observed in this study may be more prominent in earlier disease and in patients who have not received long-term disease-modifying anti-rheumatic drug therapy.

The pattern of reduced circulating IGF-I and IGFBP-3 with an unchanged $\mathrm{GH}$ total production rate in patients with $\mathrm{RA}$, as observed in our study, appears to be consistent with $\mathrm{GH}$ resistance or insensitivity $[20,25]$. Although the exact mechanisms for $\mathrm{GH}$ insensitivity in patients with RA are unclear, $\mathrm{GH}$ resistance has been observed in inflammatory and heightened catabolic states [26]. Cytokine exposure (IL-1, TNF- $\alpha$, and endotoxin) in animals decreases IGF-I synthesis [27,28], and reduced IGF-I levels occur in patients with chronic liver disease [29] and in critically ill patients [26]. Similarly, cytokines upregulate IGFBP-1 synthesis [30]. Of note is the recent report by Nemet and colleagues [31] demonstrating that short-term infusion of recombinant human $\mathrm{IL}-6$ in healthy young men to levels typically occurring during exercise decreases serum concentrations of IGF-I and increases those of $\mathrm{GH}$ and IGFBP-1. Our findings of increased inflammatory markers (ESR, CRP, and IL-6), along with reduced IGF-I and IGFBP-3, are consistent with data from some but not all prior studies. Rall and colleagues [19] found no alterations in $\mathrm{GH}$ kinetics (frequent sampling followed by deconvolution) in RA patients compared with age- and BMl-matched control subjects. However, the authors did observe a trend toward reduced IGF-I concentrations in the patients with RA $(P=$ 0.08). In the latter study, data from male and female patients 
with RA were evaluated together, patients had a longer duration of RA, and they were on stable doses of prednisone and/ or methotrexate - all of which may have confounded the authors' observations. Other studies have measured GH secretion after stimulation with GH-releasing hormone [7] or insulin-induced hypoglycemia $[9,17]$ rather than assessing spontaneous, diurnal GH secretion (as in this study), rendering any comparisons and subsequent conclusions between the studies difficult. In another study, GH concentrations in single morning (8 a.m.) samples were elevated approximately fivefold in RA patients taking glucocorticoids as compared with values in healthy controls, whereas IGF-I and IGFBP-3 levels were similar in the two groups [18]. Although we are unaware of reports in which IGF-I and IGFBP responses to exogenous $\mathrm{GH}$ have been compared in patients with RA and healthy control subjects, the present study and other studies suggest that RA is associated with $\mathrm{GH}$ resistance or insensitivity.

The effects of RA per se on the HPA axis have been reported in multiple studies $[8,9,32]$. To date, there has been no consistent demonstration of altered basal or stimulated cortisol production in RA patients as compared with healthy individuals [32]. However, the presence of 'normal' cortisol levels in the face of increased secretion of cytokines (IL-6) has been a consistent finding, leading some to suggest that RA is characterized by a state of 'relative hypocortisolism,' with an inadequate anti-inflammatory response to inflammation [32-34]. In our study, patients with RA exhibited elevated morning ESR, CRP, and IL- 6 concentrations but had no alteration in pulsatile, nycthemeral, or entropic features of spontaneous cortisol secretion. Diminished adrenal androgens have been reported in premenopausal women with RA [35-37]. In these studies, dehydroepiandrosterone sulfate (DHEAS) and to a lesser extent DHEA, concentrations in single morning samples were lower in patients with RA. Additionally, Cutolo and colleagues [38] reported that morning DHEA levels were inversely related to the ESR and that the DHEA response to adrenocorticotropic hormone (ACTH) stimulation was decreased in premenopausal women with RA. To our knowledge, the current study is the first to report spontaneous, diurnal DHEA secretion in patients with active RA. Prior findings of diminished DHEAS levels, coupled with our observation of unaltered circadian DHEA secretion in patients with RA, might be explained in part by a decreased conversion of DHEAS to DHEA resulting from excess proinflammatory cytokines, as has been reported in synovial fluid from patients with RA [37]. Moreover, our DHEA findings further suggest that in the setting of heightened inflammatory and cytokine burden, there is a relative adrenocortical androgen insufficiency in patients with RA. In support of this view, neutralization of IL-6 increases androgen secretion in patients with RA [39].

Glucocorticoids exert negative feedback control on the HPA axis by suppressing hypothalamic $\mathrm{CRH}$ production and $\mathrm{ACTH}$ secretion. The time required to achieve suppression and recovery is variable and is dependent upon the route, dosage, duration, and dosing schedule [40]. Due to suppressive effects of corticosteroid use in patients with RA, we cannot entirely rule out persistent impairment of HPA activity. Four of the patients with RA had taken glucocorticoids, with a cumulative exposure in each that was not more than 3 months, and all patients with RA had been off steroids for at least 3 months prior to study enrollment. In addition, there were no differences in early a.m. or peak plasma concentrations of cortisol, ACTH, or DHEA. Adrenal androgen secretion is more sensitive than cortisol production to the suppressive effects of glucocorticoid therapy [41]. In this study, basal and peak DHEA levels are unchanged in RA patients as compared with healthy individuals. Moreover, IL-6 is known to stimulate cortisol and androgen production in an ACTH-independent fashion $[39,42]$. These findings, in concert with the relatively short duration of past glucocorticoid therapy, suggest that the normal levels of cortisol in patients with RA in this study are less likely (but cannot be ruled out entirely) due to an impaired HPA axis by prior steroid use.

Our patients with RA exhibited reduced LBM, consistent with findings in other studies $[1,19]$. The decrease in lean mass was especially evident in the legs and was accompanied by diminished serum concentrations of creatinine, an established index of skeletal muscle mass. Cachexia, characterized by the loss of body cell mass and function, frequently occurs in patients with RA. Relative hyposomatotropism, due to reduced activity of GH/IGF-I axis and the associated negative anabolic balance resulting from abnormalities in cytokine, cortisol, and adrenal steroid production and action, have been proposed to play significant roles in rheumatoid cachexia [4].

Several limitations of this study deserve comment. Because of strict inclusion and exclusion criteria, the accrual of patients with RA was below the intended number of subjects planned. Consequently, we consider any results of interest to be hypothesis-generating, in that they require confirmation in an independent, larger group of patients. Additionally, the relative homogeneity of our study population does not allow for extrapolation of our findings to postmenopausal women or men. Finally, quality and quantity of sleep were not measured, and their possible influences on circadian rhythms of the hormones measured could not be ascertained.

\section{Conclusion}

The current study suggests that active RA in pre- and perimenopausal women is characterized by a state of relative $\mathrm{GH}$ insensitivity and diminution in diurnal cortisol and DHEA secretion, given the chronic inflammatory state of the patients. Whether these combined somatotropic and adrenocortical abnormalities in a proinflammatory cytokine milieu exacerbate the inflammatory process and play a role in the pathogenesis of rheumatoid cachexia remains to be determined. 


\section{Competing interests}

The authors declare that they have no competing interests.

\section{Authors' contributions}

MRB participated in all aspects of conceptualization, design, implementation, and data analysis and in drafting this manuscript. RM participated in data analysis and in drafting this manuscript. MW and BEM participated in all patient recruiting and management. HLB and KAW participated in patient recruiting and overnight sampling studies and performed the $\mathrm{GH}$, cortisol, and DHEA assays. CS, MM, and SA participated in patient recruitment and data collection and management. JR performed and interpreted the DEXA scans. SMS contributed to the study design and performed all statistical analyses. RG$M$ participated in all aspects of conceptualization, design, implementation, data analysis and in writing this manuscript. All authors read and approved the final manuscript.

\section{Acknowledgements}

This investigation was supported by the Intramural Research Programs of the National Center for Complementary and Alternative Medicine and the National Institute on Arthritis, Musculoskeletal and Skin Diseases, the Department of Radiology of the Warren Grant Magnuson Clinical Center, and the National Cancer Institute, NIH (Bethesda, MD, USA). The authors thank Salvatore Alesci and Giovanni Cizza for their constructive comments upon reviewing this manuscript.

\section{References}

1. Roubenoff R, Roubenoff RA, Cannon JG, Kehayias JJ, Zhuang $\mathrm{H}$, Dawson-Hughes B, Dinarello CA, Rosenberg IH: Rheumatoid cachexia: cytokine-driven hypermetabolism accompanying reduced body cell mass in chronic inflammation. J Clin Invest 1994, 93:2379-2386.

2. Pincus T, Sokka T, Wolfe F: Premature mortality in patients with rheumatoid arthritis: evolving concepts. Arthritis Rheum 2001, 44:1234-1236.

3. Riise T, Jacobsen BK, Gran JT, Haga HJ, Arnesen E: Total mortality is increased in rheumatoid arthritis. A 17-year prospective study. Clin Rheumato/ 2001, 20:123-127.

4. Rall LC, Roubenoff R: Rheumatoid cachexia: metabolic abnormalities, mechanisms and interventions. Rheumatology (Oxford) 2004, 43:1219-1223.

5. Corpas E, Harman SM, Blackman MR: Human growth hormone and human aging. Endocr Rev 1993, 14:20-39.

6. De Benedetti F, Alonzi T, Moretta A, Lazzaro D, Costa P, Poli V, Martini $A$, Ciliberto $G$, Fattori $E$ : Interleukin 6 causes growth impairment in transgenic mice through a decrease in insulinlike growth factor-I. A model for stunted growth in children with chronic inflammation. J Clin Invest 1997, 99:643-650.

7. Templ E, Koeller M, Riedl M, Wagner O, Graninger W, Luger A: Anterior pituitary function in patients with newly diagnosed rheumatoid arthritis. Br J Rheumatol 1996, 35:350-356.

8. Masi AT, Aldag JC, Jacobs JW: Rheumatoid arthritis: neuroendocrine immune integrated physiopathogenetic perspectives and therapy. Rheum Dis Clin North Am 2005, 31:131-160, x.

9. Demir H, Kelestimur F, Tunc M, Kirnap M, Ozugul Y: Hypothalamo-pituitary-adrenal axis and growth hormone axis in patients with rheumatoid arthritis. Scand J Rheumatol 1999, 28:41-46.

10. Veldhuis JD, Johnson ML: Deconvolution analysis of hormone data. Methods Enzymol 1992, 210:539-575.

11. Pincus S, Singer $\mathrm{BH}$ : Randomness and degrees of irregularity. Proc Natl Acad Sci USA 1996, 93:2083-2088.

12. Veldhuis JD, Iranmanesh A, Johnson ML, Lizarralde G: Twentyfour-hour rhythms in plasma concentrations of adenohypophyseal hormones are generated by distinct amplitude and/or frequency modulation of underlying pituitary secretory bursts. $J$ Clin Endocrinol Metab 1990, 71:1616-1623.

13. Denko CW, Malemud CJ: The serum growth hormone to somatostatin ratio is skewed upward in rheumatoid arthritis patients. Front Biosci 2004, 9:1660-1664.

14. Denko CW, Malemud CJ: Role of the growth hormone/insulinlike growth factor-1 paracrine axis in rheumatic diseases. Semin Arthritis Rheum 2005, 35:24-34.

15. Lemmey A, Maddison $P$, Breslin A, Cassar P, Hasso N, McCann R, Whellams E, Holly J: Association between insulin-like growth factor status and physical activity levels in rheumatoid arthritis. J Rheumatol 2001, 28:29-34.

16. Matsumoto T, Tsurumoto T: Inappropriate serum levels of IGF-I and IGFBP-3 in patients with rheumatoid arthritis. Rheumatology (Oxford) 2002, 41:352-353.

17. Rovensky J, Bakosova J, Koska J, Ksinantova L, Jezova D, Vigas M: Somatotropic, lactotropic and adrenocortical responses to insulin-induced hypoglycemia in patients with rheumatoid arthritis. Ann NY Acad Sci 2002, 966:263-270.

18. Toussirot E, Nguyen NU, Dumoulin G, Aubin F, Cedoz JP, Wendling $D$ : Relationship between growth hormone-IGF-I-IGFBP-3 axis and serum leptin levels with bone mass and body composition in patients with rheumatoid arthritis. Rheumatology (Oxford) 2005, 44:120-125.

19. Rall LC, Walsmith JM, Snydman L, Reichlin S, Veldhuis JD, Kehayias JJ, Abad LW, Lundgren NT, Roubenoff R: Cachexia in rheumatoid arthritis is not explained by decreased growth hormone secretion. Arthritis Rheum 2002, 46:2574-2577.

20. Baxter RC: Insulin-like growth factor (IGF)-binding proteins: interactions with IGFs and intrinsic bioactivities. Am J Physiol Endocrinol Metab 2000, 278:E967-976.

21. Le Roith D, Scavo L, Butler A: What is the role of circulating IGFI? Trends Endocrinol Metab 2001, 12:48-52.

22. Schaefer F, Baumann G, Haffner D, Faunt LM, Johnson ML, Mercado M, Ritz E, Mehls O, Veldhuis JD: Multifactorial control of the elimination kinetics of unbound (free) growth hormone (GH) in the human: regulation by age, adiposity, renal function, and steady state concentrations of GH in plasma. J Clin Endocrinol Metab 1996, 81:22-31.

23. Anders HJ, Rihl M, Loch O, Schattenkirchner M: Prediction of creatinine clearance from serum creatinine in patients with rheumatoid arthritis: comparison of six formulae and one nomogram. Clin Rheumatol 2000, 19:26-29.

24. Lim WH, Lim EM, McDonald S: Lean body mass-adjusted Cockcroft and Gault formula improves the estimation of glomerular filtration rate in subjects with normal-range serum creatinine. Nephrology (Carlton) 2006, 11:250-256.

25. Rosenfeld RG, Hwa V: New molecular mechanisms of $\mathbf{G H}$ resistance. Eur J Endocrinol 2004, 151:S11-15.

26. Baxter RC: Changes in the IGF-IGFBP axis in critical illness. Best Pract Res Clin Endocrinol Metab 2001, 15:421-434.

27. Thissen JP, Verniers J: Inhibition by interleukin-1 beta and tumor necrosis factor-alpha of the insulin-like growth factor I messenger ribonucleic acid response to growth hormone in rat hepatocyte primary culture. Endocrinology 1997, 138:1078-1084.

28. Frost RA, Lang $\mathrm{CH}$ : Alteration of somatotropic function by proinflammatory cytokines. J Anim Sci 2004, 82(ESuppl):E100-109

29. Picardi A, Gentilucci UV, Zardi EM, Caccavo D, Petitti T, Manfrini $S$, Pozzilli $P$, Afeltra A: TNF-alpha and growth hormone resistance in patients with chronic liver disease. J Interferon Cytokine Res 2003, 23:229-235.

30. Benbassat CA, Lazarus DD, Cichy SB, Evans TM, Moldawer LL, Lowry SF, Unterman TG: Interleukin-1 alpha (IL-1 alpha) and tumor necrosis factor alpha (TNF alpha) regulate insulin-like growth factor binding protein-1 (IGFBP-1) levels and mRNA abundance in vivo and in vitro. Horm Metab Res 1999, 31:209-215.

31. Nemet D, Eliakim A, Zaldivar F, Cooper DM: Effect of rhIL-6 infusion on GH-->IGF-I axis mediators in humans. Am J Physiol Regul Integr Comp Physiol 2006, 291:R1663-1668.

32. Harbuz MS, Jessop DS: Is there a defect in cortisol production in rheumatoid arthritis? Rheumatology (Oxford) 1999, 38:298-302. 
33. Cutolo M, Sulli A, Pizzorni C, Craviotto C, Straub RH: Hypothalamic-pituitary-adrenocortical and gonadal functions in rheumatoid arthritis. Ann NY Acad Sci 2003, 992:107-117.

34. Crofford LJ, Kalogeras KT, Mastorakos G, Magiakou MA, Wells J, Kanik KS, Gold PW, Chrousos GP, Wilder RL: Circadian relationships between interleukin (IL)- 6 and hypothalamic-pituitaryadrenal axis hormones: failure of IL-6 to cause sustained hypercortisolism in patients with early untreated rheumatoid arthritis. J Clin Endocrinol Metab 1997, 82:1279-1283.

35. Straub RH, Paimela L, Peltomaa R, Scholmerich J, Leirisalo-Repo $M$ : Inadequately low serum levels of steroid hormones in relation to interleukin-6 and tumor necrosis factor in untreated patients with early rheumatoid arthritis and reactive arthritis. Arthritis Rheum 2002, 46:654-662.

36. Vogl D, Falk W, Dorner M, Scholmerich J, Straub RH: Serum levels of pregnenolone and 17-hydroxypregnenolone in patients with rheumatoid arthritis and systemic lupus erythematosus: relation to other adrenal hormones. J Rheumatol 2003, 30:269-275

37. Straub RH, Weidler C, Demmel B, Herrmann M, Kees F, Schmidt $M$, Scholmerich J, Schedel J: Renal clearance and daily excretion of cortisol and adrenal androgens in patients with rheumatoid arthritis and systemic lupus erythematosus. Ann Rheum Dis 2004, 63:961-968.

38. Cutolo M, Foppiani L, Prete C, Ballarino P, Sulli A, Villaggio B, Seriolo B, Giusti M, Accardo S: Hypothalamic-pituitary-adrenocortical axis function in premenopausal women with rheumatoid arthritis not treated with glucocorticoids. J Rheumatol 1999, 26:282-288.

39. Straub RH, Harle P, Yamana S, Matsuda T, Takasugi K, Kishimoto T, Nishimoto N: Anti-interleukin-6 receptor antibody therapy favors adrenal androgen secretion in patients with rheumatoid arthritis: a randomized, double-blind, placebo-controlled study. Arthritis Rheum 2006, 54:1778-1785.

40. Krasner AS: Glucocorticoid-induced adrenal insufficiency. JAMA 1999, 282:671-676.

41. Rittmaster RS, Loriaux DL, Cutler GB Jr: Sensitivity of cortisol and adrenal androgens to dexamethasone suppression in hirsute women. J Clin Endocrinol Metab 1985, 61:462-466.

42. Mastorakos G, Chrousos GP, Weber JS: Recombinant interleukin- 6 activates the hypothalamic-pituitary-adrenal axis in humans. J Clin Endocrinol Metab 1993, 77:1690-1694. 